\title{
dld-1 suppression attenuates the detrimental effects of amyloid beta deposition in a Caenorhabditis elegans model of Alzheimer's disease
}

\author{
Waqar Ahmad*, Paul Ebert \\ From Molecular Neurodegeneration: Basic biology and disease pathways \\ Cannes, France. 10-12 September 2013
}

\section{Background}

Amyloid beta $(A \beta)$ aggregation is well studied as a major marker and determinant of Alzheimer's disease (AD) pathology. While less work has been carried out on the role of energy metabolism in $\mathrm{AD}$, there is good evidence that it also contributes to the disease. For example, low metabolic rate and ATP levels are also correlated with $A D$, which also extends to specific enzymes, metabolites, and proteins associated with glycolysis and the TCA cycle. Dihydrolipoamide dehydrogenase (DLD-1), the subject of this study, is a core metabolic enzyme with specific sequence variants that are associated with increased risk of late onset AD. DLD-1 contributes to four major metabolic multi-enzyme complexes, including $a$-ketoglutarate dehydrogenase (KGDH). A non-DLD subunit of KGDH also has variants that are associated with AD. Additionally, the activity level of the enzyme is significantly inversely correlated with the disease state in humans.

\section{Materials and methods}

We used a previously published C. elegans model of AD that consists of two strains CL2006 and CL4176, which produce human amyloid beta (1-42) in body-wall muscle cells either constitutively or by temperature upshift, respectively. $A \beta$ aggregation results in muscle impairment, observed as paralysis, which is particularly apparent when a muscle stimulant is applied. Using this assay, we chemically or genetically modified the function or abundance of DLD-1, to determine whether this could modify disease progression or remission. We also modified other metabolic functions to see whether the observed effect was specific to DLD.

\section{Results}

Expression of human $A \beta$ caused significant paralysis of $C$. elegans in the presence of each of the stimulants, aldicarb and serotonin $(5-\mathrm{HT})$. This effect was completely reversed when the dld-1 gene was suppressed in either the constitutive or the inducible $A \beta$ producing strain. The same effect was observed with chemicals that inhibited metabolic pathways involving DLD-1, but not with an uncoupler of the mitochondrial electron transport chain that depletes ATP production capacity. Thus, it was not energy depletion, per se, that caused the effect. Rather, the critical factor seems to be inhibition of an, as yet loosely defined, DLD-1 containing metabolic pathway. The chemicals that were effective in alleviating the $A \beta$ mediated pathology in the model also decreased $A \beta$ aggregation. Interestingly, one of the chemicals in particular effectively decreased $A \beta$ aggregation and reduced the behavioural pathology regardless of whether the $A \beta$ was pre-expressed or co-expressed with the chemical treatment.

\section{Conclusions}

Our results show that inhibition of DLD-1 in our model has protective effects against $A \beta$ toxicity although the precise mechanism is not yet fully understood. 


\title{
Acknowledgement
}

The authors are thankful to Australian government and University of

Queensland for providing IPRS grant for this project.

Published: 13 September 2013

\begin{abstract}
doi:10.1186/1750-1326-8-S1-P3
Cite this article as: Ahmad and Ebert: dld-1 suppression attenuates the detrimental effects of amyloid beta deposition in a Caenorhabditis elegans model of Alzheimer's disease. Molecular Neurodegeneration 2013 8(Suppl 1):P3.
\end{abstract}

Submit your next manuscript to BioMed Central and take full advantage of:

- Convenient online submission

- Thorough peer review

- No space constraints or color figure charges

- Immediate publication on acceptance

- Inclusion in PubMed, CAS, Scopus and Google Scholar

- Research which is freely available for redistribution

Submit your manuscript at www.biomedcentral.com/submit 